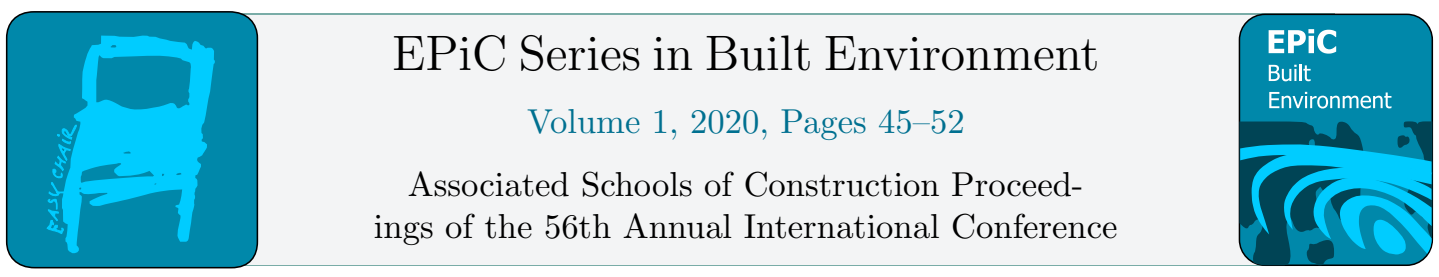

\title{
Insights into Education System for Sustainable Development: The case of UCEM, UK
}

\author{
Renuka Thakore, Ph.D. and Aled Williams, BSc(Hons) MSc PGCHE FCIOB \\ University College of Estate Management \\ Reading, UK
}

\begin{abstract}
'Education for Sustainable Development' (ESD) drives priority to aligning education programmes for convergence of Sustainable Development Goals (SDGs) and Education agendas. This paper argues that, to this end, the importance of strategic, tactical and operational level changes and sustaining the human and material resources used to transform any kind of learning environments, should be factored into all institutional-wide strategies. In other words, this should be an integral aspect of the implementation of sustainability elements in institutional-wide activities. However, ideally, to fully establish the foundation for Sustainability, the range of activities by which ESD can be delivered should not be restricted but should be extended to building a society that values peace, equality, human rights, gender, environment and cultural diversity. This would assist furthering SDGs; however, to be effective, this approach requires the incorporation of a process like NUS Responsible Future Certification. The scope of this paper will therefore outline what wholeinstitution collaborative approach is, and then why it is relevant, considering how it may be used to contribute to a more sustainable future of the built environment education system. Document analysis research methodology was used to inform a theoretical conceptual framework for education system for sustainable development.
\end{abstract}

Key Words: Education, Institution-wide Collaborative Approach, Sustainable Development Goals

\section{Introduction}

A Decade of Education for Sustainable Development (DESD) (2005-2014) was adopted by the UN General Assembly in 2002 (UNESCO, 2005). DESD aimed "to integrate the values inherent in sustainable development into all aspects of learning to encourage changes in behaviour that allow for a more sustainable and just society for all in terms of environmental integrity, economic viability and a just society for present and future generations" (UNESCO, 2005). At the end of the DESD, it was concluded that a solid foundation has been laid for 'Education for Sustainable Development' (ESD) (United Nations Educational, 2014), achieved by raising awareness, influencing policies and generating significant numbers of good practice projects in all areas of education and learning. This paper takes the view that the whole-institution approaches practice ESD is the one that takes the responsibility for mainstreaming sustainability into all aspects of the learning environment. This are the means of embedding sustainability in curriculum and learning processes, facilities and operations, 
interaction with the surrounding community, governance and capacity-building. In the United Kingdom, for example, the process is facilitated by the Responsible Futures (RF) Certification (SOS, 2019). This paper argues that RF certification, or a similar process, should be used as a tool to promote a more sustainable form of ESD.

The achievement of effective ESD is one which, in this paper's view, requires incorporation of the basic foundation for sustainability which drives sustainability at local, national, and global levels (Gaffney, 2014) to achieve the 17 Sustainable Development Goals (SDGs) 2030 Agenda (United Nations, 2015); as well as builds sustainability literacy, including environmental stewardship, futurefacing outlook, global citizenship and social justice and wellbeing (Longhurst et al., 2014) in students. This paper therefore refers to a whole-institution approach which can be used to consider the sustainability capacities of the HEI, including delivery of ESD in the students who will serve future society. The results can also be fed into design and delivery of sustainability leadership in Education, and to extent the capability development of future practitioners and decision-makers in resolving problems that interface with and impact on SDGs.

This paper will therefore explain what whole-institution approach to ESD is, assess its significance in transferring competences in students to exercise active, critical, and committed citizenship in their workplace and living. It will conclude that a whole-institution approach to ESD will benefit from the incorporation of the principles of ESD mandating the alignment of education programmes and convergence between SDGs and Education agendas. This is the first stage in a systemic implementation of education system for sustainable development.

\section{Literature Review}

The professional association of construction educators and industry practitioners such as the Associated Schools of Construction (ASC) along with the Higher Educational Institutions (HEIs) work together for the development and advancement of construction education system for sustainable development (ASC, 2016). The term "sustainability literacy" is accepted for the purpose of this paper as referring to building blocks of the education system for sustainable development, which include environmental stewardship, future-facing outlook, global citizenship and social justice and wellbeing (Longhurst et al., 2014). Education is a vehicle that transfers competences in students to exercise active, critical, and committed citizenship in their workplace and living (Zamora-Polo \& SanchezMartin, 2015). Due to the critical role of education in societal transformation, importantly, future practitioners and decision-makers need to have the capabilities to resolve problems interfacing with and impacting on SDGs.

In the context of integrating the principles of ESD in all aspects of education, HEIs particularly need to focus on an institution-wide collaborative approach, explicitly contributing to the four core activities: education, research, operations and extensions (Ruiz, 2016). However, this should be induced through the alignment of education programmes, convergence between SDGs and Education agendas, and the application of innovative pedagogical approaches (del Mar Alonso-Almeida et al., 2015). In the HEIs, education is assessed without considering whether or not there will be any contribution to HEIs' Sustainability capacities and the impact of their contribution to SDGs. However, some UK HEIs, for example, Anglia Ruskin University and UWE Bristol, have developed innovative measures to assess sustainability, and to some extent accelerate as well as widen sustainability impact. This is an innovative method of delivering of ESD to successfully achieve fulfilment of the HEIs' contribution to SDGs (Sterling, 2013). 
HEIs, worldwide, are attempting to engage with ESD and value Sustainability. Consequently, some HEIs have succeeded in pioneering integration of Sustainability in all facets of their organisation; however, these achievements have not provided enough incentive to the education system to genuinely engage with the Sustainability discourse (Bekessy, Samson, \& Clarkson, 2007). Nevertheless, these initiatives have become representative of the change in the debate, moving to 'what should be developed in order to mainstream ESD' (Van Weenen, 2000). The process of RF accreditation has only recently been developed. In 2014, 13 pilot partnerships across FE and HE in the UK were established under the auspices of the Responsible Futures Advisory Board. Then the RF framework containing nationally agreed standard concepts and assessment criteria was adopted as the national accreditation framework for ESD and producing comparable statistics (SOS, 2019).

\section{Built Environment Education and Online Adult Learning}

There is an increased need for Sustainability-literate graduates and professionals who can demonstrate relevant skills and attributes in addition to building a decision-making capacity, while appreciating the complex relationships between the economic, social and environmental dimensions of Sustainable Development (Dyer, Selby, \& Chalkley, 2006). The Built Environment is defined as "the humanmade space in which people live, work and recreate on a day-to-day basis" (Roof \& Oleru, 2008). This encompasses the environment in which the human activities are set and undertaken, ranging in scale from buildings to cities and beyond. Therefore, it is widely recognised as a critical discipline to address SD challenges, including achieving circular economy (Bringezu, 2015). Buildings, being very long-term products and elements of 'cities and communities', need a sustainable approach. This demands that students develop ESD through the curriculum to inform their decision-making capacity and capabilities for sustainability as they are future industry leaders.

Online learning or web-based approaches, e-learning and distance learning are increasingly facilitating digitally mediated learning environments. With the recent development of SD in HEIs, such initiatives are promoted (Azeiteiro, Leal Filho, \& Caeiro, 2014). Adult learning has specific characteristics such as a self-directed study approach, whereby students take ownership of their learning, identifying learning needs, as well as developing learning strategies (Caffarella \& O'Donnell, 1987). The education for Built Environment that is self-directed and delivered online allows students to perceive and understand the meaning of the issues that are relevant and useful for personal or professional decision-making. Lifelong learning empowers individuals and communities for the promotion of social justice and democratic change (Delors, 1998; Peña-López, 2015) promoting economic growth and competitiveness (Casey \& Asamoah, 2016).

\section{Higher Education Institutions and Responsible Futures Certification}

"Responsible Futures certification" (SOS, 2019) by National Union of Students (NUS), now named as SOS (Students Organising for Sustainability) is an externally assessed certification (accreditation mark) of a whole institution's commitment to social responsibility and sustainability. It is a recognition of having an enabling culture in the institution for sustainability learning, i.e. knowledge and understanding, skills, and attributes needed to contribute positively to social responsibility. Working in partnerships with the HEIs and its students' unions, accreditation is awarded after a twoday audit process. This involves review of documentary evidence through the online workbook tool (http://www.greenimpact.org.uk/responsiblefutures) and interviews with the relevant key individuals. Accreditation is gained by the HEI when it scores more than 200 points out of the total of 300 points. The Award is valid for two years (refer to NUS Responsible Futures for further information). 
The objective of 'NUS Responsible Futures certification' is to prepare, monitor and accredit the HEI to develop Sustainability capacities in the four interrelated core functional activities: education, research, operations and extensions. It has been identified that such a process induces the change with a continuous improvement cycle (Holm, Sammalisto, Grindsted, \& Vuorisalo, 2015) and strengthens the institution-wide change culture for Sustainability (Ceulemans, Molderez, \& Van Liedekerke, 2015). In summary, there is little account in the literature of an institution-wide collaborative approach, aligned with core four interrelated functional activities of an online university explicitly contributing to the delivery of ESD and successfully achieving fulfilment of the HEIs' contribution to SDGs.

\section{Research Design}

Qualitative research methodology was adopted for this research. According to Bowen (2009), a thorough systematic analysis of documents can provide understanding of the institutional context and related concepts conceived and implemented by the institution (Bowen, 2009). University College of Estate Management (UCEM) policy documents such as strategic plans, student and staff survey reports and periodic review reports of modules and courses were analysed to understand the underlying intentions and were coded to identify contribution of ESD to different empirical themes such as education, research, operations and extension. This informed a theoretical conceptual framework for education system for sustainable development adopted by the UCEM. Accordingly, this analysis provide evidence to support NUS Responsible Futures accreditation. The evidence for the RF accreditation was audited by the UCEM students' body, presenting a high level of objectivity and supporting UCEM leadership for sustainability literacy. It is, however, due to lack of insufficient data, this research is context sensitive to UCEM.

\section{Results and Discussion}

Based on the analysis, a conceptual framework 'Institution-wide Collaborative Approach' integrating four core functional activities was developed (see Figure 1).

\begin{tabular}{|c|c|}
\hline $\begin{array}{c}\text { Education } \\
\text { Undergraduate and graduate training for } \\
\text { sustainability }\end{array}$ & $\begin{array}{c}\text { Research } \\
\text { Anstitution-wide } \\
\text { Operations } \\
\text { Collaborative Approach }\end{array}$ \\
\hline $\begin{array}{c}\text { Sustainable and environmental } \\
\text { management systems }\end{array}$ & $\begin{array}{c}\text { Extensions } \\
\text { Involvement in external local and global } \\
\text { sustainability issues }\end{array}$ \\
\hline
\end{tabular}

Figure 1: Four core functional activities for Sustainability leadership. Adopted from Ruiz (2016).

Following this, several strategic, tactical and operational changes and technical advances were identified to capture UCEM sustainability capacities and leadership.

\section{Education}

In order to ensure that the UCEM students were conversant in best practice to nurture a sustainable built environment, the Learning, Teaching and Assessment (LTA) Strategy (2016-2020) strategically incorporated principles of ESD. This was supported by the tactical change of developing partnerships 
with students and accreditation bodies such as NUS and formation of a staff and student Responsible Futures Working Group (RFWG).

All (90) taught module descriptors were assessed against the four aspects of sustainability literacy identified by HEA / QAA (Longhurst et al., 2014). This review showed that the level of sustainable development content in the module descriptors was found to be significant across postgraduate courses, which was $94 \%$. For undergraduate courses, the sustainable development content in the number of module descriptors was found slightly less: For first year undergraduate modules, it was found to be $53 \%$; for second year undergraduate modules, it was $46 \%$; and for the third year undergraduate modules, it was $75 \%$. This evaluation showed that in lower level of courses of university, ESD is introduced as part of a general introduction. Higher levels build upon these concepts to more specific issues and increasing specialization reflected in the requirements of industry and professional bodies, particularly to achieve accreditation.

An institution-wide survey was completed by 461 students in November 2017 using the NUS annual survey. This covered attitudes, experiences and expectations associated with sustainability at UCEM. The survey was voluntary and, as UCEM is a leading global supported online education provider, respondents were recruited via internal 'all student' survey. The results showed that UCEM was 8th out of 38 Institutions who participated in 2017 (and first if the size of the student population is considered). A separate survey of teaching staff on their understanding of Social Responsibility and Sustainability (SRS) was sent to 145 potential respondents. Responses from $47 \%$ comprising of Internal Construction and Real Estate Tutors and 53\% comprising of External Associate Tutors were received. The wide range of responses contributed towards contextualising the definition and scope of SRS within UCEM, increased engagement with academic colleagues/tutors and generated content used to support embedding of SRS. A massive open online course (MOOC) delivering full contents of sustainability curriculum/education was completed by many staff members.

\section{Research}

UCEM research strategy is to undertake applied, real world sustainability research and partnerships aligned with the needs of local, national and international agendas. The UCEM research and scholarship approach aids meeting UCEM's overarching aims of the strategic vision, enhance research capability and research dissemination. At tactical level, the objectives of two Research Centres, Online Learning Research Centre (OLRC) and Property and Construction Research Centre (PCRC), focused on key strengths of UCEM research staff contributing to the strategic research vision. The research areas include Online learning, Sustainability, Real Estate, Heritage, Conservation and Adaptation and Sustainable and Innovative Construction.

An exemplary resources around sustainable construction and gamification has been developed by one of the UCEM staff, called 'ECO Materials Trumps Digital Cards Game'. This is being used for groupbased workshop sessions and interactive and experiential learning. Another innovative research based online interactive resource developed by the UCEM staff is the 'Green Room' serving as an excellent online resource for all students. It contains several case studies and success stories linking to the students' curriculum currently being updated. UCEM's engagement with the Prince's Foundation for Building Community offers students and staff an opportunity to learn from research and learning in the field of Sustainable Urbanism. In addition, UCEM has developed collaborative partnerships with the Chartered Institute Building (CIOB) and The Worshipful Company of Constructors on researchbased Sustainability Scholarships. 
Establishing UCEM as a leader in the Sustainability agenda includes two research based interactive case studies which are open educational resources: a) 'Horizons: achieving excellence' - Exploring social, environmental and economic rationale and opportunities for embedding sustainability in its own building "Horizons" and achieving Building Research Establishment Environmental Assessment Method (BREEAM) 'Excellent' rating in August 2016; b) 'Poundbury - New approaches to urbanism' - Examining the need to develop sustainable communities that are resilient within land use, local ecology, mass migration, job creation and other sources of stress affecting community life.

\section{Operations}

A Corporate Social Responsibility (CSR) Statement in 2017, Human Resources (HR) Policy on Voluntary and Charity Work strategically guides UCEM operations. These documents were supported by Sustainability Working Group (SWG) Terms of reference; Sustainability Statement; Sustainability declaration, 'all-staff' pledge, etc.. At tactical level, a specific, measurable and achievable (SMART) plan, endorsed by the Senior Leadership Team and led by high-level Sustainability Champion was developed. Supported by the SWG and relevant committees, and had a RAG (Red, Amber and Green) rating, the progress of key performance indicators allowed the Partnership to measure success. For the UCEM operations to be aligned with sustainable and environmental management systems, the engagement of staff and students was crucial. A formal committee of cross-departmental membership (comprising 13 members, including 4 students) was formed within the institution to lead and shape elements of SRS issues. A letter of support from the Lead Student Representative was obtained to endorse the students' engagement with the NUS Responsible Futures partnership with the university. Arrangements were made for the students' representative auditors to meet members of the RFWG forum and formal meetings were recorded and reports were published to keep the whole institution updated with the happenings.

Surveys were conducted to understand students' and staff's knowledge on sustainability, institution's operations, course curriculum and pedagogy around ESD. These findings were shared more widely with staff and students, and relevant committees (e.g. Sustainability Working Group; Learning, Teaching \& Enhancement Committee) via various modes of communication such as email and a sustainability website. A 'show and tell' workshop was planned with relevant staff including the curriculum audit / staff survey outcomes to have a deeper dialogue and obtain feedback so that any recommendations / next steps can be moved forward. This is now being considered as an iterative process to monitor and enhance UCEM sustainability capacity as a part of sustainability implementation plans. Equally important, UCEM operates from "Horizons" (discussed earlier in Research section), organises workshops on World Environment Day, and publishes Sustainability actions taking place in the institution through different channels of media within the institution and on its website to engage various external stakeholders. There is Sustainability Hub section in the UCEM Monthly e-Bulletin.

\section{Extensions}

Two strategic policies, UCEM Corporate Social Responsibility (CSR) Statement and HR Policy on Voluntary and Charity Work, encourage UCEM activities, engagement and extension programs within the local community. This includes fundraising work for charities, voluntary organisations or community projects; environmental work and conservation projects; and community care work. All employees are offered one day's paid leave per calendar year to undertake volunteering work as part of the UCEM commitment to these policies. Launchpad is an example of the opportunity given to staff to work in the community. This year 2019 Centenary Celebrations took place and several explicit 
volunteering events took place to mark and share the celebration within the community. In particular, the most important was the involvement of UCEM in exchange visits that occurred with other UK universities to share and disseminate best practice.

Other extension programs include the Sustainability Seminar/Webinar delivered by the CEO Friends of the Earth which was attended 'live' by about 100 staff and students and continues to have offline webinar views. Several free CPD resources are available for staff and students through UCEM Sustainability website. An EcoMaterial Trumps workshop was delivered at the Environmental Association of Universities and Colleges (EAUC) Conference. Several other events were formally planned for dissemination of various research findings and engagement with the community for economic, social and environmental contribution. UCEM's commitment to educating others through the project approach was awarded by the 'Green Apple Gold Award', leading UCEM to becoming Green World Ambassadors.

\section{Conclusion}

This paper considers it feasible that the whole-institution collaborative approach provides a means to assess and achieve measurable outcomes towards sustainability leadership. Therefore, this can be used to increase professionalism and contribution to a better Built Environment future in line with the vision and mission of ASC. This paper indicates that UCEM's journey on Sustainability leadership and the acknowledgment with the accreditation to NUS 'Responsible Futures' Award contributes to a new approach to ESD. This is in association with putting Sustainability at the heart of every curriculum and UN SDG 4.7 - Learning to live together sustainably by 2030. Importantly, activities such as embedding Sustainability aspects in the built environment education, creating Sustainability awareness in staff and students, adopting environmental management and sustainability practices in the building operations, and extending research and engagement with students, staff and wider community, have increased UCEM's capacity to be accountable to the whole society for both its actions and its achievements. UCEM has been successful in increasing the student's skills, and insights into practices in buildings, cities and communities, contributing to decision-making capacities to achieve SDGs. Consequently, this paper argues that methods such RF should be encouraged and incorporated into a corporate strategy that forms part of every contract associated with the university activities.

\section{References}

ASC. (2016). What is ASC? Retrieved from https://www.ascweb.org/about/general-information/ Azeiteiro, U., Leal Filho, W., \& Caeiro, S. (2014). E-Learning and Education for Sustainability: Peter Lang.

Bekessy, S., Samson, K., \& Clarkson, R. (2007). The failure of non-binding declarations to achieve university sustainability: A need for accountability. International Journal of Sustainability in Higher Education, 8(3), 301-316.

Bowen, G. (2009). Document analysis as a qualitative research method. Qualitative research journal, 9(2), 27-40.

Bringezu, S. (2015). Possible target corridor for sustainable use of global material resources. Resources, 4(1), 25-54.

Caffarella, R., \& O'Donnell, J. (1987). Self-directed adult learning: A critical paradigm revisited. Adult Education Quarterly, 37(4), 199-211. 
Casey, C., \& Asamoah, L. (2016). Education and sustainability: Reinvigorating adult education's role in transformation, justice and development. International Journal of Lifelong Education, 35(6), 590606.

Ceulemans, K., Molderez, I., \& Van Liedekerke, L. (2015). Sustainability reporting in higher education: a comprehensive review of the recent literature and paths for further research. Journal of Cleaner Production, 106, 127-143.

del Mar Alonso-Almeida, M., Marimon, F., Casani, F., \& Rodriguez-Pomeda, J. (2015). Diffusion of sustainability reporting in universities: current situation and future perspectives. Journal of cleaner production, 106, 144-154.

Delors, J. (1998). Learning: The treasure within: UNESCO.

Dyer, A., Selby, D., \& Chalkley, B. (2006). A centre for excellence in education for sustainable development. Journal of Geography in Higher Education, 30(2), 307-312.

Gaffney, O. (2014). Sustainable development goals: improving human and planetary wellbeing. Global Change Magazine, 82, 20-23.

Holm, T., Sammalisto, K., Grindsted, T. S., \& Vuorisalo, T. (2015). Process framework for identifying sustainability aspects in university curricula and integrating education for sustainable development. Journal of Cleaner Production, 106, 164-174.

Longhurst, J., Bellingham, L., Cotton, D., Isaac, V., Kemp, S., Martin, S., . . Taylor, C. (2014). Education for sustainable development: Guidance for UK higher education providers.

Peña-López, I. (2015). Rethinking Education. Towards a global common good?

Roof, K., \& Oleru, N. (2008). Public health: Seattle and King County's push for the built environment. Journal of environmental health, 71(1), 24-27.

Ruiz, L. (2016). Incorporation of Environmental and Sustainable Indicators in Universities. Journal of Environmental Protection, 7(06), 825.

SOS, N., UK. (2019). nus Responsible Futures. Retrieved from https://sustainability.nus.org.uk/responsible-futures.

Sterling, S. (2013). The sustainable university: Challenge and response. In The sustainable university (pp. 43-76): Routledge.

UNESCO. (2005). United Nations Decade of Education for Sustainable Development, 2005-2014: Draft International Implementation Scheme, January 2005. Retrieved from Brasilia, Brazil.

United Nations. (2015). Sustainable Development Goals, 17 Goals to transform our world. Retrieved from https://www.un.org/development/desa/disabilities/envision2030.html.

United Nations Educational, S., and Cultural Organization. (2014). UNESCO roadmap for implementing the Global Action Programme on Education for Sustainable Development.

Van Weenen, H. (2000). Towards a vision of a sustainable university. International Journal of Sustainability in Higher Education, 1(1), 20-34.

Zamora-Polo, F., \& Sanchez-Martin, J. (2015). Analysis of the implementation of the Master of Industrial Engineering in Spain. What an engineer should know? what we teach? Dyna, 90(2), 153157. 